* Corresponding author

Phone +421556024359

E-mail address: maria.carnogurska@tuke.sk

(prof. Ing. Mária Čarnogurská, CSc.)

Article information

Article history: AMS-Volume16-No.1-00138-12

Received 12 February 2012

Accepted 28 March 2012

\section{Modelling of Nitrogen Oxides Production during Wood Combustion}

\author{
Mária Čarnogurskáa*, Miroslav Př́hodab ${ }^{\mathrm{b}}$, Marcel Koško ${ }^{\mathrm{a}}$ \\ ${ }^{a}$ Technical University in Košice, Faculty of Mechanical Engineering, Department of Power Engineering, Slovak Republic \\ ${ }^{b}$ VŠB - Technical University of Ostrava, Faculty of Metallurgy at Mining University in Ostrava, Department of Thermal Engineering at Faculty \\ of Metallurgy and Material Engineering, (zech Republic
}

\section{BIOGRAPHICAL NOTES}

Mária Čarnogurská, prof. Ing. CSc. she is a graduate of Faculty of Mechanical Engineering, Technical University in Kosice (TUKE). Currently works as a deputy of head at Department of Power Engineering at Faculty of Mechanical Engineering within a. m. university. Her long-term professional focus is within the area of power engineering. The research is concentrated on mathematical and physical modelling of processes and effects applied in power engineering, the flow of different media in energy machines and appliances as well as the exploitation of non-utilised heat energy in diverse industrial applications.

Miroslav Príhoda, prof. Ing. CSc. he is a graduate of Faculty of Metallurgy at Mining University in Ostrava. Currently works as a Head of Department of Thermal Engineering at Faculty of Metallurgy and Material Engineering, VŠB - Technical University of Ostrava and is a authority for heat processes within industrial and municipal sphere. His research is concentrated on Mathematical and Physical Modelling of Thermal Processes, Thermal Work of Basic Units of Continuous Casting Equipment, Temperature Conditions in Metal Recuperators, Utilisation of Steel Enthalpy at Metallurgical Plants, Determination of Thermal Conductivity and Thermal Diffusivity at High Temperatures. Marcel Koško, Ing. he is a graduate of Faculty of Mechanical Engineering, Technical University in Kosice (TUKE). Currently works as a doctoral at Department of Power Engineering. He actively participates in research of new technologies in area of renewable energy resources and mathematical modelling of energy processes.

\section{KEY WORDS}

Mathematical modelling, nitrogen oxides, dimensional analysis, wood combustion

\section{ABSTRACT}

The process of elaboration and consequent verification of mathematical model of $\mathrm{NO}_{x}$ production during wood combustion based on the dimensional analysis theory is presented in this paper. The model is based on selected physical quantities which can be measured continually during boiler operation. Primarily, the model was elaborated for boiler type VERNER V210 of $20 \mathrm{~kW}$ performances and its validity was also verified for the same construction type of boiler of lower performance (14 kW). Lump wood

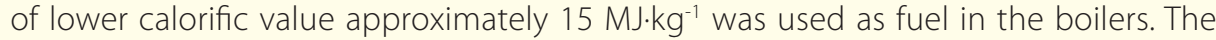
results showed that the dimensional analysis can be applied to describing such a complicated phenomenon as the $\mathrm{NO}_{\mathrm{x}}$ production during wood combustion is.

\section{Introduction}

For the purpose of obtaining heat the burning of wood, bark and wood waste are 
ranked among standard procedures for use or disposal of phytomass. While the use of phytomass for energy purposes was a priority in the past, its importance gradually declined in the power industry and wood became only a suitable additional fuel.

Formation of nitrogen oxides during dendromass combustion is particularly associated with nitrogen compounds contained in the fuel. Their elimination in low power devices is quite complicated. In high performance devices their elimination is possible by a substoichiometric combustion and supply of air in several levels. For elimination of thermal nitrogen oxides it is important to prevent formation of areas with high temperature and high excess of air [10]. The issues of thermal lignin decomposition during combustion of wood at $400^{\circ} \mathrm{C}$ are dealt with in e.g. [5], [6]. The description of nitrogen oxides concentration in the exhaust gases, generated during the low-temperature oxidation, depending on the amount of nitrogen contained in fuel, is dealt with in the work [8].

Currently there is a large number of small heat sources combusting dendromass on the Slovak market. It is possible to burn wood in the form of logs, chips, pellets, briquettes, etc. Small heat sources for combustion of wood, and various forms of its waste, must meet the requirements, set out by relevant European and Slovak standards, as well as the relevant health regulations. Among the basic parameters observed in small heat sources are such parameters as heat performance and the method of combustion process regulation. Other monitored parameters are boiler efficiency, the requirements in terms of environmental impact and safety requirements. From the energy point of view it is necessary to ensure the most effective utilisation of the energy contained in the fuel. The quality of combustion in a confined space of the boiler depends mainly on the temperature of combustion, the method of separation of the various phases of burning, thoroughness of combustible gases mixing with oxygen at the required reaction temperature, excess air and manner of distribution of primary and secondary air [6].

Given the complexity of the exact description of the process of creating nitrogen oxides during different conditions of wood combustion, it is not possible to develop a generally applicable model that would describe such production for various types of boilers, for various forms of fuel (sawdust, wood pieces, chips), and various types of wood (spruce, fir, beech, pine, etc.). The issue of burning wood and developing of a mathematical formula for production of nitrogen oxides is dealt with by several authors, e.g. [2], [8], [9]. These models are often very complicated. They are usually based on "chemistry" of wood conversion during its combustion and the determination of nitrogen oxides volume using them is rather difficult. Therefore even today the possible applications of new procedures and methods to describe the formation of nitrogen oxides when burning dendromass are searched.

One of the possible tools, suitable for modeling of various processes, is the dimensional analysis, see [1], [7], used primarily in the field of fluid mechanics and thermomechanics. The authors attempted to apply this theory to modeling of the nitrogen oxides formation during combustion of the wood in boilers with small output power. So far, no work describing this phenomenon by employing of the dimensional analysis exists.

The created model is based on the selected physical quantities, which are continuously measurable during operation of the combustion equipment. In the presented model the attention is paid mainly to the impact of particular operational parameters on the production of nitrogen oxides during combustion of a particular type of wood with a specific calorific value [3], [4], [11].

\section{Nitrogen Oxides Production}

It is documented that the wood nitrogen content is different and depends mainly on tree species. The average nitrogen content in the wood of conifers is approximately $\mathrm{N}=0.03 \%$, and in the hard wood of deciduous trees is up to $\mathrm{N}=0.15 \%$. The average presence of nitrogen in the bark of conifers is approximately $\mathrm{N}=0.40 \%$, and in the bark of deciduous trees up to $N=0.72 \%$ [12]. During the combustion of wet wood and bark in grate furnaces of the heating units the nitrogen oxides are formed only through low-temperature oxidation of the part of nitrogen bound in the fuel. Their production is dependent upon the amount of nitrogen contained in the fuel and the portion of nitrogen in the fuel transformed into emissions. The fact that the nitrogen content in wood and bark of trees is not the same means that also the concentrations of nitrogen oxides in exhaust gasses from these trees are different. 
The wood as a fuel is characterized by moderately high calorific value, a high portion of volatile combustible material and low ash content.

The methodology of the model development for description of the NOx production during combustion of wood involves the correlation between the nitrogen contained in the wood and nitrogen oxides contained in the exhaust gasses only through the temperature of exhaust gasses at the exit from the boiler. It is supposed that this temperature is directly related to the temperature in the furnace. The type of wood and the influence of nitrogen content in the wood may not be taken into account directly in the actual development of the model. This influence is reflected in the model through the in situ measured values of selected variables forming a model. The measured nitrogen oxides reflect the quality and the nature of the combustion process, the impact of the burnt trees and their corresponding nitrogen content in wood and bark. The influence of the combusting wood type, and thus the nitrogen content in the fuel, on the actual production of nitrogen oxides is expressed only by obtained constants A, B in the equation (17), which in the developed model will be for each type of wood and its calorific value different. These constants for the type of combusted dendromass must be obtained by an experiment.

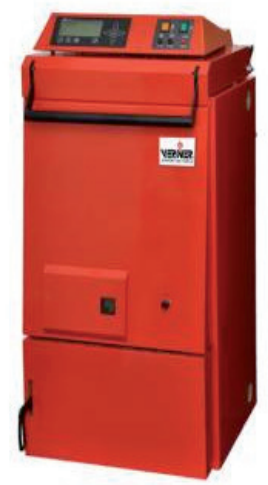

Fig. 1: Lump wood boiler of VERNER V210 type.

The developed model for the determination of nitrogen oxides, presented later in this article, is of general validity, but the constants $A$ and $B$ contained in it apply only to combusted wood with particular nitrogen content in it as its current calorific value. Therefore, if the other type of wood is combusted than wood burned during the guarantee measurements for the VERNER boiler
Table 1: Parameters of VERNER boilers.

\begin{tabular}{|c|c|c|}
\hline BOILER & V140 & V210 \\
\hline Rated power (kW) & 14 & 20 \\
\hline Efficiency (\%) & 90 & 90 \\
\hline $\begin{array}{l}\text { Variability by continuous operation } \\
(\mathrm{kW})\end{array}$ & $7-14$ & $10-20$ \\
\hline $\begin{array}{l}\text { Variability by shutdown mode of } \\
\text { operation }(\mathrm{kW})\end{array}$ & $2-7$ & $3-10$ \\
\hline Total weight (kg) & 330 & 370 \\
\hline $\begin{array}{l}\text { Height (without exhaust cover) } \\
(\mathrm{mm})\end{array}$ & 1230 & 1230 \\
\hline Width (mm) & 580 & 580 \\
\hline Depth (mm) & 825 & 925 \\
\hline $\begin{array}{l}\text { Diameter of exhaust gasses hub } \\
(\mathrm{mm})\end{array}$ & 160 & 160 \\
\hline Volume of the feed chamber (I) & 55 & 75 \\
\hline $\begin{array}{l}\text { Fuel consumption at rated output } \\
\left(\mathrm{kg} \cdot \mathrm{h}^{-1}\right)\end{array}$ & $3,6-3,8$ & $4,2-5,7$ \\
\hline $\begin{array}{l}\text { Minimum return temperature of } \\
\text { water }\left({ }^{\circ} \mathrm{C}\right)\end{array}$ & 55 & 55 \\
\hline
\end{tabular}

\begin{tabular}{|c|c|c|}
\hline BOILER & V140 & V210 \\
\hline $\begin{array}{l}\text { Exhaust gasses temperature at } \\
\text { the exit }\left({ }^{\circ} \mathrm{C}\right)\end{array}$ & 150 & 155 \\
\hline Water volume (I) & 30 & 32 \\
\hline Calorific value $\left(\mathrm{MJ} \cdot \mathrm{kg}^{-1}\right)$ & 14,52 & 15,45 \\
\hline $\begin{array}{l}\text { Exhaust gasses mass flow rate } \\
\left(\mathrm{kg} \cdot \mathrm{s}^{-1}\right)\end{array}$ & 0,01 & 0,015 \\
\hline $\begin{array}{l}\text { Minimum operating thrust of } \\
\text { the exhaust }(\mathrm{Pa})\end{array}$ & 10 & 10 \\
\hline Emission class of the boiler & 3 & 3 \\
\hline $\begin{array}{l}\text { Range of outlet water tempera- } \\
\text { ture control }\left({ }^{\circ} \mathrm{C}\right)\end{array}$ & $60-90$ & $60-90$ \\
\hline $\begin{array}{l}\text { Fuel used during warranty } \\
\text { period (dry wood) }\end{array}$ & \multicolumn{2}{|c|}{$\begin{array}{l}\text { diameter: up to } 15 \mathrm{~cm} \text {, } \\
\text { length: up to } 35 \mathrm{~cm}\end{array}$} \\
\hline Other type of fuel: & \multicolumn{2}{|c|}{$\begin{array}{l}\text { wooden briquettes, } \\
\text { sawdust, dry wood } \\
\text { chips }\end{array}$} \\
\hline The maximum noise level(dB) & 55 & 55 \\
\hline
\end{tabular}

(dry beech wood logs of length about $34 \mathrm{~cm}$ ), it is necessary to re-establish the constants $A$ and $B$ appearing in the equation (17) of the developed model.

The VERNER's boilers (Fig. 1), of V210 type with output of $20 \mathrm{~kW}$ and of V140 type with output 14 $\mathrm{kW}$, are hot water boilers fuelled by wood and are designed for efficient, comfortable and environ- 
mentally friendly heating of houses, residential units, operations and similar facilities with heat loss ranging from $14 \mathrm{~kW}$ to $20 \mathrm{~kW}$. Both boilers are based on the principle of two stage combustion, where there is fuel gasification followed by combustion of generated gases. Technical parameters of the two boilers are shown in the Table 1.

\section{Procedure Statements by Mathematical Model}

Among the relevant variables affecting the production of nitrogen oxides during combustion of wood in the analysed combusting equipment, based on the knowledge from specialized literature, the physical quantities accompanying the combustion process have been chosen, which are measurable on the operated combustion equipment. These are following quantities, which should be expressed in the system of basic units for the application in the dimensional analysis:

- boiler performance: $\mathbf{P}_{\mathbf{k}}\left(\mathrm{W} \cong \mathrm{kg} \cdot \mathrm{m}^{2} \cdot \mathrm{s}^{-3}\right)$,

- the amount of combustion air: $\mathbf{Q}_{\mathbf{v z}}\left(\mathrm{m}^{3} \cdot \mathrm{s}^{-1}\right)$,

- calorific value: $\mathbf{Q}_{\mathbf{u}}\left(\mathrm{J} \cdot \mathrm{kg}^{-1} \cong \mathrm{m}^{2} \cdot \mathrm{S}^{-2}\right)$,

- exhaust gasses temperature at the end of the boiler: $\mathbf{T}_{\text {sk }}(\mathrm{K})$,

combustion air temperature: $\mathbf{T}_{\mathbf{v} \mathbf{z}}(\mathrm{K})$,

nitrogen oxides: $\mathbf{N} \mathbf{0}_{\mathbf{x}}\left(\mathrm{kg}^{-\mathrm{m}^{-3}}\right)$.

The complete physical equation expressing the dependence of selected relevant dimensional quantities with different dimensions, including the production of $\mathrm{NO}_{x^{\prime}}$ has, in terms of dimensional analysis, the expression

$$
f\left(P_{k}, Q_{v z}, Q_{u}, T_{s k}, T_{v z}, N O_{x}\right)=0
$$

From the requirements of dimensional diversity implies that the variables in the equation may not stand alone, but in the form of product

$\pi=P_{k}^{x_{1}} \cdot Q_{v z}^{x_{2}} \cdot Q_{u}^{x_{3}} \cdot T_{s k}^{x_{4}} \cdot T_{v z}^{x_{5}} \cdot N O_{x}^{x_{6}}$

The expression of dimensionless arguments is based on the dimensional matrix, which has for basic units of selected quantities in the total number of columns $n=6$ and rows $m=4$ the form

$$
\begin{array}{llllll}
P_{k} & Q_{v z} & Q_{u} & T_{s k} & T_{v z} & N O_{x}
\end{array}
$$

\begin{tabular}{c||cccccc||}
$\mathrm{m}$ & 2 & 3 & 2 & 0 & 0 & 3 \\
$\mathrm{~s}$ & 3 & 1 & 2 & 0 & 0 & 0 \\
$\mathrm{~kg}$ & 1 & 0 & 0 & 0 & 0 & 1 \\
$\mathrm{~K}$ & 0 & 0 & 0 & 1 & 1 & 0
\end{tabular}

The matrix rows are not linearly dependent, so the rank of the matrix $h=m=4$. With the number of relevant quantities $n=6$ the total number of created arguments will be $I=n-m$, i.e. 2 dimensionless arguments $\pi$. In their determination we proceed so the rectangular dimensional matrix [3], the relationship (3), is split into two parts. One part is a square matrix - the $\mathbf{A}$ matrix in the relation (4), and the second part is the complementary matrix (matrix $\mathbf{D})$. The selection of columns from the equation (3) for the square matrix $\mathbf{A}$ should be such that its determinant is nonzero. Also the selection of the vector of unknown quantities $x i$ (matrix $\mathbf{B}$ and E) should be adapted to the selection of columns. This procedure is expressed by equation (4) and (5).

$$
\mathrm{A} \cdot \mathrm{B}=(-1) \cdot \mathbf{D} \cdot \mathbf{E}
$$

$$
\begin{aligned}
& \left\|\begin{array}{rrrr}
2 & 3 & 2 & 0 \\
-3 & -1 & -2 & 0 \\
1 & 0 & 0 & 0 \\
0 & 0 & 0 & 1
\end{array}\right\| \cdot \| \\
& =(-1) \cdot\left\|\begin{array}{rr}
0 & -3 \\
0 & 0 \\
0 & 1 \\
1 & 0
\end{array}\right\| \cdot\left\|\begin{array}{c}
x 1 \\
x 2 \\
x 3 \\
x 5
\end{array}\right\|=
\end{aligned}
$$

The value of matrix $\mathbf{A}$ determinant is $\Delta_{A}=-4$. The selection of the excess unknowns $x_{4}$ and $x_{6}$ from the equation (5) will be carried out twice, whereby both selections must be linearly independent

\begin{tabular}{|l|l|l|}
\hline & $x_{4}$ & $x_{6}$ \\
\hline 1st selection & 0 & 1 \\
2nd selection & 1 & 0 \\
\hline
\end{tabular}

The matrix of independent selections is always square and in the above expression represents identity matrix in the form

\begin{tabular}{||ll}
0 & 1 \\
1 & 0
\end{tabular}$\|$

It may also be chosen otherwise, but its determinant should always be nonzero $(\Delta \neq 0)$. The determinant of the matrix (6) has a value of $\Delta=1$, thus the condition solvability of the task is fulfilled.

The obtained system of linear equations from the relation (5) is in the form 
$2 \cdot x_{1}+3 \cdot x_{2}+2 \cdot x_{3}=3 \cdot x_{6}$

$-3 \cdot x_{1}-x_{2}-2 \cdot x_{3}=0$

$x_{1}=-x_{6}$

$x_{5}=-x_{4}$

By the solution of the system of linear equations we obtain two independent criteria $\pi_{1}$ and $\pi_{2^{\prime}}$ and minus sign at the relevant unknown quantity $x i$ in the expression of arguments according to (8) means that the corresponding quantity in the criterion of similarity occurs in the denominator. The plus sign expresses the quantity in the numerator.

\begin{tabular}{|c|c|c|c|c|c|c|}
\hline$\pi_{1}$ & -1 & 1 & 1 & 0 & 0 & 1 \\
\hline$\pi_{2}$ & 0 & 0 & 0 & 1 & -1 & 0 \\
\hline
\end{tabular}

Complex dimensionless arguments arising from (8) are in the form

$\pi_{1}=\frac{Q_{v z} \cdot Q_{u} \cdot N O_{x}}{P_{k}}$

$\pi_{2}=\frac{T_{\mathrm{sk}}}{T_{\mathrm{vz}}}$

The general dimensionless description of the function expressing the production of nitrogen oxides during combustion of wood may be given in the form

$\psi\left(\pi_{1}, \pi_{2}\right)=0$

The dimensionless argument $\pi_{1}$ contains variable $\mathrm{NO}_{x^{\prime}}$ so this argument may be expressed as a function of an argument $\pi_{2}$

$\pi_{1}=\varphi\left(\pi_{2}\right)$

The function (12) will be expressed as a system of one-parameter curves. Its shape is determined by calculation of $\pi_{2}$ value from values obtained during measurement (Table 2), and this value is entered as an independent variable. The argument $\pi_{1}$, thus
Specifically, the expression of equation (12) may be expected e.g. in the form of a power function which will be transformed by logarithmic calculation into the equation of a line

$\pi_{1}=A \cdot \pi_{2}^{B}$

also the $\mathrm{NO}_{x^{\prime}}$ is subsequently expressed as the dependently variable function of the $\pi_{2}$ function.

$\log \pi_{1}=\log A+B \cdot \log \pi_{2}$

The calculation of the intercept $A$ in relation (14), indicating the distance of the intersection of the regression line on co-ordinate $\pi_{1}$ from the zero point, and the regression coefficient $\mathbf{B}$, indicating the slope of regression line, may be made by the least squares method, and also directly by utilization of the Microsoft Excel program.

\section{Results of the Developed Model Application}

For the purpose of mathematical model development and its verification the VERNER company has provided the data about the individual physical quantities (Table 2). These are average values obtained from continuous measurements at two operating conditions of the boiler. The measurements have been carried out twice at the nominal power (about $20000 \mathrm{~W}$ ); once at about half of the output power. The measurements have been carried out by an external company (Strojírenský zkušební ústav, s.p. Brno).

In the Table 3 are shown calculated values of dimensionless arguments $\pi_{1}, \pi_{2}$ in accordance with relations (9) and (10) and their logarithms are determined, necessary for the analytical procedure of calculating the regression coefficient and intercept. Based on the measured quantities it is possible to express the actual course of the function $\log \pi_{1}=$ $\varphi\left(\log \pi_{2}\right)$ as well as the course of dependency of dimensionless arguments themselves directly in the logarithmic coordinates (Fig. 2).

From the dependence expressed in logarithmic coordinates, follows directly the intercept $\mathbf{A}$ and

Table 2: Measured values of relevant quantities and calculated value of NOx according to the relation (17) for the V210 boiler.

\begin{tabular}{|l|l|l|l|l|l|l|l|}
\hline $\mathbf{P}_{\mathbf{k}}$ & $\mathbf{Q}_{\mathbf{v z}}$ & $\mathbf{Q}_{\mathbf{u}}$ & $\mathbf{T}_{\mathbf{s k}}$ & $\mathbf{T}_{\mathbf{v z}}$ & \multicolumn{1}{|c|}{$\mathbf{N O x}_{\text {nam }}$} & \multicolumn{1}{|c|}{ NOx $_{\mathbf{v y p}}$} & \multicolumn{1}{c|}{ difference } \\
\hline$(\mathrm{W})$ & $\left(\mathrm{m} 3 \cdot \mathrm{s}^{-1}\right)$ & $\left(\mathrm{J} \cdot \mathrm{kg}^{-1}\right)$ & $(\mathrm{K})$ & $(\mathrm{K})$ & $\left(\mathrm{kg} \cdot \mathrm{m}^{-3}\right)$ & $\left(\mathrm{kg} \cdot \mathrm{m}^{-3}\right)$ & $(\%)$ \\
\hline 20050 & 0.0097 & 15450000 & 394.75 & 296.65 & 0.00024235 & 0.00022490 & 7.20 \\
\hline 20010 & 0.0101 & 15450000 & 397.15 & 296.85 & 0.00020538 & 0.00022026 & -7.24 \\
\hline 10870 & 0.0057 & 15450000 & 365.15 & 296.85 & 0.00015814 & 0.00015890 & -0.48 \\
\hline
\end{tabular}


the regression coefficient $\mathbf{B}$. Their values are $A=$ $0.00063236, B=3.1490$.

When using the actual course of the functions $\log \pi_{1}=\varphi\left(\log \pi_{2}\right)$, see Fig. 3, the information about the value $a=-0.3199$ and the value $b=0.1319$ is obtained from the diagram. For conversion of these values to the intercept and the regression coefficient the following applies:

$$
\begin{array}{ll}
a=\log \mathrm{A} & \rightarrow \mathrm{A}=10^{\mathrm{a}}=10^{-0.3199}=0.007518 \\
b=B & \rightarrow \mathrm{B}=0.1319 .
\end{array}
$$

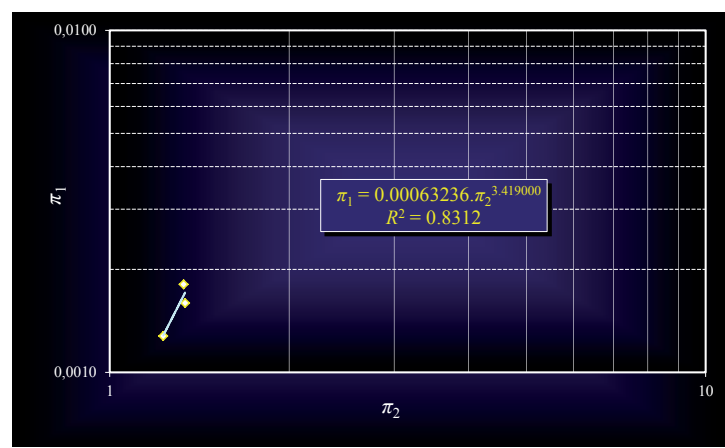

Fig. 2: Intercept constant $A$ and the regression coefficient $B$.

Table 3: Values of dimensionless arguments for linear regression.
Such defined constants in the developed model are valid only for combustion of dry beech wood

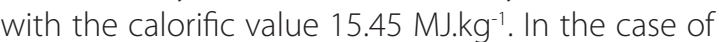
combustion of wood with different calorific value different values of individual quantities acting in the model would be obtained during measurement. Also other values of dimensionless arguments $\pi_{1^{\prime}}$ $\pi_{2}$ would be obtained and production of nitrogen oxides would be described by the relationship (18), in which the change of combusted fuel and production of nitrogen oxides would be reflected by the new values of intercept constant $\mathbf{A}$ and the regression coefficient $\mathbf{B}$.

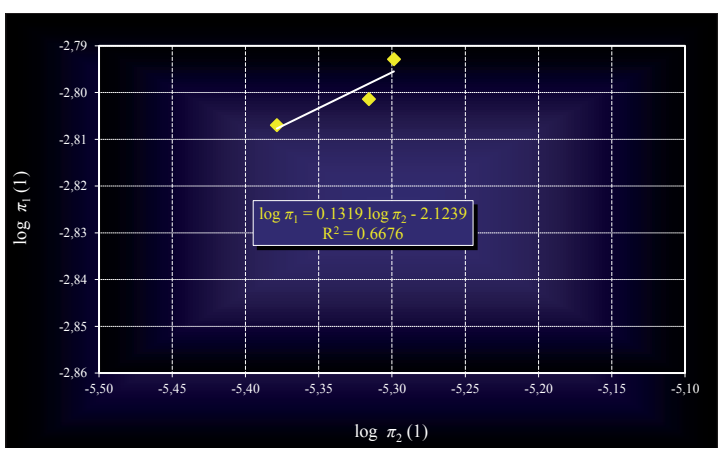

Fig. 3: Constant $A$ and $B$.

\begin{tabular}{|l|l|l|l|l|l|}
\hline$\pi_{\mathbf{2}}$ & $\pi_{\mathbf{1}}$ & $\log \boldsymbol{\pi}_{\mathbf{1}}$ & $\log \boldsymbol{\pi}_{\mathbf{2}}$ & $\log \boldsymbol{\pi}_{\mathbf{1}} \cdot \log \boldsymbol{\pi}_{\mathbf{2}}$ & $\log ^{2} \boldsymbol{\pi}_{\mathbf{2}}$ \\
\hline$(1)$ & $(1)$ & $(1)$ & $(1)$ & $(1)$ & $(1)$ \\
\hline $1.3307 \mathrm{E}+00$ & $1.8089 \mathrm{E}-03$ & -2.7424 & 0.1241 & -0.3403 & 0.0154 \\
\hline $1.3379 \mathrm{E}+00$ & $1.5952 \mathrm{E}-03$ & -2.7972 & 0.1264 & -0.3536 & $0 ., 0160$ \\
\hline $1.2301 \mathrm{E}+00$ & $1.2775 \mathrm{E}-03$ & -2.8936 & 0.0899 & -0.2602 & 0.0081 \\
\hline & & -8.4332 & 0.3404 & -0.9541 & 0.0395 \\
\cline { 3 - 6 } & & $\mathbf{\Sigma}$ & $\mathbf{\Sigma x}$ & $\mathbf{\Sigma x} \cdot \mathbf{y}$ & $\mathbf{\Sigma} \mathbf{x}^{2}$ \\
\hline
\end{tabular}

If the experiment for obtaining of the new constants $A$ and $B$ at the combustion of different quality and type of wood will not be carried out, but the original values of constants will be used, a greater variation in nitrogen oxides expressions in terms of the developed model, comparing to the real situation, should be expected. Also such case of model application will be analysed in this article.

The formation of nitrogen oxides during combustion of wood may be described on the basis of relation (13) for the analysed boiler by the model developed using the dimensional analysis, by the dependency of relevant dimensional quantities as follows

$$
\frac{Q_{\mathrm{vz}} \cdot Q_{\mathrm{u}} \cdot N O_{\mathrm{x}}}{P_{\mathrm{k}}}=A \cdot\left(\frac{T_{\mathrm{sk}}}{T_{\mathrm{vz}}}\right)^{B}
$$

The functional dependence of $\mathrm{NO}_{x}$ production on the selected quantities expressed from the relation (15) will be expressed as

$$
N O_{\mathrm{x}}=A \cdot P_{\mathrm{k}} \cdot T_{\mathrm{sk}}^{B} \cdot Q_{\mathrm{vz}}^{-1} \cdot Q_{\mathrm{u}}^{-1} \cdot T_{\mathrm{vz}}^{-B} \quad\left(k g \cdot \mathrm{m}^{-3}\right)(16)
$$

By the substitution of actual values of the regression coefficient and intercept constants in the expression (16) we obtain

$$
N O_{x}=63236 \cdot 10^{-8} \cdot\left(\frac{P_{k}}{\mathrm{Q}_{\mathrm{vz}} \cdot \mathrm{Q}_{\mathrm{u}}}\right) \cdot\left(\frac{\mathrm{T}_{\mathrm{sk}}}{\mathrm{T}_{\mathrm{vz}}}\right)^{3.4190}\left(\mathrm{~kg} \cdot \mathrm{m}^{-3}\right)
$$


$N O_{x}=C \cdot\left(\frac{P_{k}}{\mathrm{Q}_{\mathrm{vz}} \cdot \mathrm{Q}_{\mathrm{u}}}\right)^{\mathrm{m}} \cdot\left(\frac{\mathrm{T}_{\mathrm{sk}}}{\mathrm{T}_{\mathrm{vz}}}\right)^{\mathrm{n}} \quad\left(k g \cdot m^{-3}\right)(18)$

where the individual constants are represented by following values:

$C=63236 \cdot 10^{-8,} \quad m=1.0, \quad n=3.4190$.

The criterion equation for production of nitrogen oxides may be expressed in the simplest terms as follows

$$
N O_{x}=C \cdot K^{\mathrm{m}} \cdot P^{\mathrm{n}} \quad\left(k g \cdot \mathrm{m}^{-3}\right)
$$

where individual constants are represented by the values:

$C=63236.10^{-8}, K=P_{\mathrm{k}} / Q_{\mathrm{v} z^{\prime}} Q_{u^{\prime}}, P=T_{\mathrm{sk}} / T_{\mathrm{vz}}, m=1.0, n=3.4190$.

The relationship (18) is a mathematical model of NOx production during combustion of the wood in low power boilers of the same or similar design as the design of the VERNER boilers.

\section{Verification of the Developed Mathematical Model for the Verner V140 Boiler}

The developed model of nitrogen oxides production was verified also for the low power VERNER V140 boiler. Also with this type of boiler the average values of measured quantities necessary for the relation (18) have been obtained for two rated outputs and for about half of boiler's output by the company "Strojírenský zkušební ústav, s. p. Brno". The verification of the model was carried out in practice by substituting different values for the existing V140 boiler into relation (18), where the values of constants $C$, $m$ and $n$ were the same as in the case of the V210 boiler. The measured and calculated values for nitrogen oxides for the boiler with lower output power are in the Table 4.

The difference between measured and calculated values in accordance with the mentioned relation for the VERNER V210 boiler (Table 4) may be explained by the fact that during the selection of relevant quantities certainly not all effects, on which the production of nitrogen oxides during combustion of wood depends, were taken into account. Howev- er the priority in the development of the model has been focused on the quantities easily measurable, therefore it is reasonable to expect a greater deviation between the measured quantities of nitrogen oxides and the calculated values according to relation (18).

\section{Discussion and Conclusion}

The mathematical model developed with utilization of the dimensional analysis proved the possibility of utilization of this method for determining of the nitrogen oxides produced volume during the combustion of wood in the equipment of low power. The Tables 2 and 4 show that the difference between the determination of nitrogen oxides production by direct measurements on the V210 boiler and employing of a mathematical model, ranges from $-7.24 \%$ to $7.20 \%$, and for the V140 boiler from $-4.02 \%$ to $7.79 \%$. The difference between measured and calculated values may be explained also by the fact that during the selection of relevant quantities certainly not all effects, on which the production of NOx during combustion of wood depends, were taken into account.

At the development of the mathematical model with utilization of the dimensional analysis the precise knowledge of the physical nature of the researched phenomenon is essential and it necessary to take into account all relevant quantities on which the phenomenon depends. Among the relevant quantities in combustion of wood, except for the temperature of exhaust gasses at the end of the boiler, also e.g. the temperature of flame should be included. The continuous measurement of the flame temperature in the combustion zone is rather difficult in the field operation; therefore the inclusion of this relevant quantity in the development of a mathematical model has been omitted. It was assumed that this temperature is related to a final temperature of exhaust gases. Omitting of the flame temperature among relevant quantities represents a certain level of error in description of the nitrogen oxides production and this deficiency substantially

Table 4: Measured values of relevant Calculated Quantities and value of NOx according to the relation (18) for V140 boiler.

\begin{tabular}{|c|c|c|c|c|c|c|c|}
\hline $\mathbf{P}_{\mathbf{k}}$ & $Q_{v z}$ & Qu & $\mathbf{T}_{\mathrm{sk}}$ & $\mathbf{T}_{\mathrm{vz}}$ & $\mathrm{NOx}_{\text {nam }}$ & $\mathrm{NOx}_{\mathrm{vyp}}$ & divergence \\
\hline (W) & $\left(\mathrm{m}^{3} \cdot \mathrm{s}^{-1}\right)$ & $\left(J \cdot \mathrm{kg}^{-1}\right)$ & $(K)$ & $(\mathrm{K})$ & $\left(\mathrm{kg} \cdot \mathrm{m}^{-3}\right)$ & $\left(\mathrm{kg} \cdot \mathrm{m}^{-3}\right)$ & (\%) \\
\hline 13210 & 0.0065 & 14520000 & 384.45 & 295.55 & 0.00021154 & 0.00021833 & -3.21 \\
\hline 13530 & 0.0067 & 14520000 & 386.55 & $297 ., 25$ & 0.00020743 & 0.00021577 & -4.02 \\
\hline 6930 & 0.0038 & 14520000 & 376.25 & 298.15 & 0.00019306 & 0.00017802 & 7.79 \\
\hline
\end{tabular}


contributes to the difference between the nitrogen oxides production calculated in accordance with the model developed - relationship (18) and direct measurement.

\section{References}

[1] BARENBLATT, G. I. Dimensional analysis. Gordon and Breach Science Publishers, New York, London, Paris, Montreaux, Tokyo, 1987, 136p.

[2] BRANC, M., Bojko, M.: Characterization of mathematical modelling of the combustion process of the wooden material in the application on the model of fireplace stoves. In. Boilers and power plants [online]. Brno, 2009, p. 8, [cit. 201103-15]. Available at: <http://www.allforpower.cz/UserFiles/ files/2009/branc.pdf $>$.

[3] ČARNOGURSKÁ, M., PŘÍHODA, M.: Application of the dimensional analysis to the model of phenomena in the field of energy. Košice, Vienala, 2011, 214p. ISBN 978-80-5530699-5.

[4] ČARNOGURSKÁ, M., PŘ́lHODA, M., BRESTOVIČ, T.: Modeling of nitrogen oxides formation applying dimensional analysis. Chemical and Process Engineering 2011, 32 (3): 171-180, DOI: 10.2478/v10176-011-0013-7. ISSN 0208-6425.

[5] JANDAČKA, J., MALCHO, M., MIKULÍK, M.: Technologies for the preparation and use of biomass energy. Žilina: Jozef
Bulejčík, 2007, 222p. ISBN 978-80-969595-3-2.

[6] KAČíKOVÁ, D., KAČíK, F.: Effect of thermal exposure on spruce wood lignin. Acta Facultatis Xytologiae, 2008, 50 (1): 65-72.

[7] LANGHAR, H. L.: Dimensional Analysis and Theory of Models, Robert E. Kreiger Publishing Company, Malabar. 1987.

[8] NOSEK, R., JANDAČKA, J., CHABADOVÁ, J., PAPUČíK, Š.: Effect of fuel supply to power heat and formation of emissions in domestic boiler. Archivum combustionis, 2010a, 30 (4): 347352, ISSN 0208-4198.

[9] NOSEK, R. JANDAČKA, J., SZLEK, A.: Numerical modelling of coal combustion in domestic boiler. Archivum combustionis, 2010b, 30 (3):167, ISSN 0208-4198.

[10] OCHODEK, T., KOLONIČNÝ, J., BRANC, M.: Ecological aspects of the substitution of fossil fuels for biomass. Ostrava: VŠBTU. 2007, 144p. ISBN 978-80-248-1595-4.

[11] PŘílHODA, M. Use of the dimensional analysis in Thermomechanics. In Proceedings of the IV. nationwide seminar of departments of fluid mechanics and thermome-chanics. Košice: 1984: 72-79.

[12] SLOVÁK, J. et al. The proportion of nitrogen in the fuel wood. Acta Mechanica Slovaca, 1999, (1) 3: 211-214.

[13] VERNER a. s. Boilers fuelled by wood pieces. Company material. [cit. 2011-03-03]. Available at: <http://www.kotleverner.cz/produkty/kotle-na-kusove-drevo>. 